\title{
Analysis of the possibility for seismic early warning in the Balkan Peninsula
}

\section{Анализ на възможността за сеизмично ранно предупреждение на Балканския полуостров}

\author{
Dragomir Dragomirov ${ }^{1}$, Lyuba Dimova ${ }^{1}$, Milen Tsekov ${ }^{1}$, Margret Velizarova ${ }^{1}$, Fabio Romanelli', \\ Reneta Raykova ${ }^{1}$ \\ Драгомир Драгомиров ${ }^{1}$, Люба Димова ${ }^{1}$, Милен Цеков ${ }^{1}$, Маргрет Велизарова $^{1}$, \\ Фабио Романели', Ренета Райкова ${ }^{1}$
}

\author{
${ }^{1}$ Sofia University St. Kliment Ohridski, Faculty of Physics, 5 J. Bourchier blvd., 1164 Sofia, Bulgaria; \\ E-mail: rraykova@phys.uni-sofia.bg \\ ${ }^{2}$ University of Trieste, Department of Mathematics and Geosciences, via E. Weiss 4, 34128 Trieste, Italy
}

\begin{abstract}
This study analyses the possibility for seismic early warning (EW) in the Balkan Peninsula. A number of characteristics of seismic record were evaluated for EW utility. Some tests checked the possibility to locate events reliably by Golitsyn's method, using one seismic station (SS). The distance and relevant travel time from some crustal faults to the nearest SS and big towns were appraised. EW procedures for most of the seismic zones in the Balkan Peninsula are not reliable, excepting the Vrancea zone, because of the small density of the SS, crustal depth of the earthquakes and fault crowdedness of the region.
\end{abstract}

Keywords: seismic zone, earthquake early warning, travel time of seismic waves.

\section{Увод}

Балканският полуостров, като част от Алпо-Хималайския сеизмичен пояс, често е подложен на въздействието на силни земетресения с магнитуд над 6. Когато такова събитие е близо до големи градове, щетите и жертвите могат да са значителни. Земетресенията са обусловени от сложни нелинейни процеси и тяхното краткосрочно прогнозиране е почти невъзможно на сегашния етап на развитие на сеизмологията. В последните две десетилетия, след земетресението в о-в Суматра през 2004 г., усилено се разработват различни алгоритми и процедури за ранно предизвестяване на земетресения (Zollo et al., 2010; Nakamura et al., 2011). Разработването на EEWS (Earthquake Early Warning Systems) е свързано и с увеличаване на гъстотата на сеизмичните станции (CC), чиито брой в последните години нарасна значително. Но гъстотата на СС на Балканския полуостров все още не е достатьчна дори за добро локализиране на микроземетресенията. В тази работа се анализират редица параметри, които могат да се използват при наличието само на една СС в близост до сеизмична зона (C3). Дава се и оценка за ефективността на EEWS в различни части от Балканския полуостров.

\section{Методология и данни}

Параметрите, които се оценяват във връзка с EEWS, може да се разделят на няколко групи. Първата група е свързана с анализа на сеизмичния запис. Сеизмограмата от всяко земетресение е уникална, но земетресенията от една и съща активна зона, регистрирани на една и сыща станция, имат подобни характеристики. Използват се записи от някои СС, включени във Виртуалната Сеизмична Мрежа на Софийски Университет (ВСМСУ), които са близки до сеизмоактивни зони. Информацията за анализираните земетресения (време в огнището, координати на епицентъра, дълбочина, магнитуд) са взети от Международния Сеизмологичен Център (ISC, www. isc.ac.uk, 2021), а сеизмичните записи - от международните сеизмологични центрове IRIS (www.iris.edu, 2021) и EIDA (www.orfeus-eu.org/data/eida, 2021). От сеизмичните записи се измерват и пресмятат редица характеристики на сеизмограмите от дадена сеизмична зона - време на пристигане на Р- и на S-вълните; разликата между времената на пристигане на S- и Р-вълните; продължителност на първият пакет P- и на първият пакет S-вълни; средна амплитуда на сигнала преди пристигане на Р-вълната и преди пристигане на S-вълната; средна и максимална ам- 
плитуда на Р-вълната в първия пакет и на S-вълната в първия пакет; периоди на Р- и S-вълните в първите пакети; отношение сигнал/шум за $\mathrm{P}$ и $\mathrm{S}$-вълните. Всички тези параметри се определят за редица земетресения с различен магнитуд, като се пресмятат средните характеристики на земетресения от дадена $\mathrm{C} 3$, регистрирани на дадена СС. Тези характеристики се използват при настройването на EEWS за разпознаване на земетресения от дадена C3, а зависимостта между максималната амплитуда на Р-вълните в първия пакет и магнитуда на събитията ще спомогне за бързото определяне на магнитуда. Определянето на тези параметри не винаги е тривиално, особено когато земетресенията са по сравнително плитки разломи в различни техни участъци.

Друг важен анализ на сеизмограмите е оценка на възможността за реалистично определяне на епицентъра на земетресението, използвайки метода на Голицин (Golitsyn, 1960). При този метод се използват първите амплитуди от трите компонента на сеизмограмата, за да се пресметне обратният азимут от станцията до събитието, а по разликата във времената на пристигане на S- и Р-вълните се определя разстоянието. Прилагайки метода и сравнявайки резултатите с епицентралните координати от ISC, измерванията за дадена C3 може да се настроят за да се подобри точността.

Друга група характеристики са свързани с времената на разпространение на сеизмичните вълни. Използва се софтуерния пакет TauP (Crotwell et al., 1999), за да се пресметне времето на разпространение на различните P- и S-фази (Pg, Sg, Pn, Sn, P, S, $\mathrm{p}, \mathrm{s})$, като се използва конкретен глобален, регионален или локален модел. Времето на разпространение на различните сеизмични фази се пресмята от хипоцентъра до използваната станция и от използваната станция до най-близките градове. Целта е да се определи времето за реакция и дали то е достатъчно за евакуация на хора или само за автоматично изключване на отговорни съоръжения като електроцентрали, газопроводи, химически заводи и други. Когато С3 е разположен по разлом, при наличието само на една близка станция, е важно да се оцени и времето на разпространение на сеизмичните вълни от различни сегменти на разлома до СС. Тези времена могат да варират значително, когато размерите на разлома са съществени.

Последна група характеристики свързва интензитета на земетресението за дадено населено място и неговите характеристики (магнитуд, дълбочина, епицентрално разстояние) за дадена С3. Тази зависимост е доста различна за различните сеизмични зони и зависи както от характеристиките на С3, така и от локалните геоложки условия на населеното място. В най-общия случай може да се даде само приблизителна оценка, тъй като конкретните данни са сравнително малко.

\section{Резултати}

Най-благоприятният пример за изследване е сеизмична зона Вранча, в която сравнително често ста- ват земетресения с магнитуд над 6. Епицентрите на земетресенията са разположени в елиптична зона със сравнително малки размери и дълбочината на хипоцентрите е със средна стойност около $160 \mathrm{~km}$. Това са и причините да бъде вече изградена работеща система за ранно предупреждение, използвайки няколко CC, разположени в зоната (Marmureanu et al., 2011 и цитираната там литература). Ние използваме само станция MLR, чиито записи са свободно достъпни от IRIS (до 2003 г.) и EIDA (след 2003 г). Анализирани са около 20 събития, регистрирани на тази станция. Пример за сеизмограма на едно от събитията е даден на фиг. 1а. Анализираните земетресения са с магнитуд $\left(\mathrm{m}_{\mathrm{b}}\right)$ между 3,1 и 5,1 , a епицентралните разстояния са между 20 и $60 \mathrm{~km}$. От анализа на сеизмограмите са определени средните стойности на редица параметри. На вертикалната компонента са определени: средна амплитуда на шума преди Р-вълната $1,10^{-6} \mathrm{~m} / \mathrm{s}$; средна амплитуда на Р-вълните в първия пакет 9,4 $10^{-5} \mathrm{~m} / \mathrm{s}$; продължителност на първият пакет Р-вълни $1,03 \mathrm{~s}$; максималната амплитуда на Р-вълните в първия пакет е $2,0710^{-4} \mathrm{~m} / \mathrm{s}$. Зависимостта между максималната амплитуда на Р-вълните и магнитуда е дадена на фиг. 1б, но за определяне на емпирична зависимост са необходими повече данни, както и необходимостта да се отчете и разликата в хипоцентралните разстояния на отделните съби-

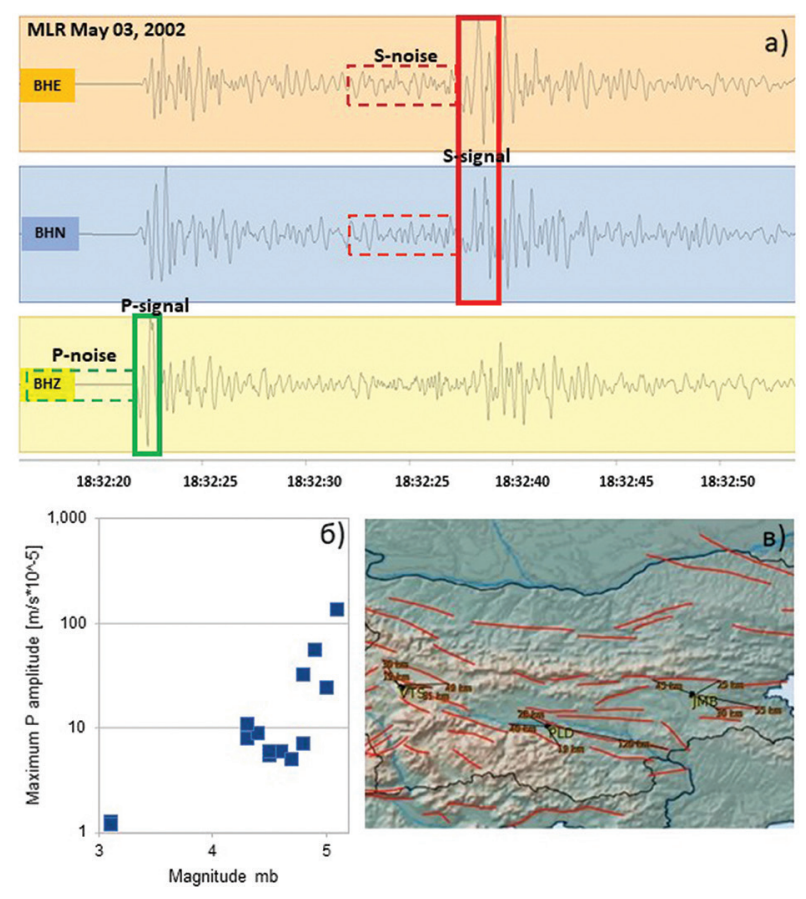

Фиг. 1. а) Трикомпонентна сеизмограма на земетресение от Вранча, регистрирано на станция MLR. C плътна линия са означени първите пакети на Р- (зелена) и S- (червена) вълните. Пунктираните линии означават интервалите, за които е оценена средната амплитуда на шума. б) Зависимост на максималната амплитуда на Р-вълните от магнитуда $\mathrm{m}_{\mathrm{b}}$. в) Разположението на главните разломи в България (www.share-eu.org) и разстоянието между някой СС и краищата на най-близките разломи. 
тия. На хоризонталните компоненти S-вълната е по-ясна на Е-компонентата и измерените характеристики са следните: средна амплитуда на сигнала преди S-вълната $3,410^{-5} \mathrm{~m} / \mathrm{s}$; средна амплитуда на $\mathrm{S}$-вълните в първия пакет 1,6 10 ${ }^{-4} \mathrm{~m} / \mathrm{s}$; продължителност на първият пакет S-вълни 1,50 s. Отношението сигнал/шум и за $\mathrm{P}$ и за $\mathrm{S}$-вълните е над 5 , което гарантира добро качество на автоматичното определяне на фазите $\mathrm{P}$ и $\mathrm{S}$, както и сравнително точно определяне на хипоцентралното разстояние.

Локализацията на събитията с метода на Голицин и сравнението с епицентрите, дадени от различни сеизмични центрове, също показват добра възможност за използване на тази станция за определяне на епицентьра на събитието от зоната Вранча. Например за едно събитие от 30.11.2002 г. изчислените координати на епицентъра са $45.77^{\circ} \mathrm{N}$, $26.14^{\circ} \mathrm{E}$, а решението, дадено от ISC е $45.68^{\circ} \mathrm{N}$, $26.45^{\circ} \mathrm{E}$, от BUC е $45.62^{\circ} \mathrm{N}, 26.54^{\circ} \mathrm{E}$ и от NEIS $45.72^{\circ} \mathrm{N}, 26.56^{\circ} \mathrm{E}$. Измерванията и решението може да се прецизират, за да се доближат до решенията, дадени от различните сеизмични центрове.

От сеизмограмите на CC MLR се установява, че времето на разпространение на Р-вълните от епицентъра до станцията е около $10 \mathrm{~s}$, a S-вълните пристигат около 15 s след Р-вълните. Използвайки глобалният модел IASP91 и софтуерът TauP се изчислява, че сеизмичните вълни достигат Букурещ около 15 s след като са преминали през CC MLR, до Русе - след 23 s, до Свищов - след 27 s, а София след $45 \mathrm{~s}$.

За оценка на интензитета на земетресението в дадено място, от дадена С3 се изисква събиране на разнороден материал. Теоретичните оценки на интензитета може да бъдат доста различни от реалните, в зависимост от локалните геоложки условия. Среднодълбоките земетресения от Вранча с магнитуд над 7 най-общо могат да окажат въздействия с интензитет V-VI степен на разстояния $300-400 \mathrm{~km}$.

Сеизмична зона Вранча е различна от останалите сеизмични зони на Балканския полуостров. Обикновено дълбочината на земетресенията на континенталната част на региона не надвишава 30-40 km, а за България по-голямата част от земетресенията имат дълбочина до около $20 \mathrm{~km}$. Друга характерна разлика е, че обикновено това са земетресения, свързани с различни по дължини разломи - от няколко десетки до стотици километри. Тогава разстоянията от различните сегменти на даден разлом до най-близката СС и до най-близките населени места са подобни (фиг. 1в). Единствена възможност за предупреждение е за пристигащите вторични S-вълни и повърхностни вълни, но те ще пристигат за по-малко от $10 \mathrm{~s}$ след Р-вълната. Друга трудност за EEWS идва от факта, че около дадена СС съществуват няколко разлома и бързата локализация ще бъде почти невъзможна. Характерна особеност за плитките земетресения е, че техния интензитет намалява сравнително бързо с отдалечаване от епицентъра и обикновено щети и жертви се наблюдават само на малки разстояния от епицентъра до около 50-100 km, като се изключват места със специфични геоложки условия, които концентрират сеизмичната енергия. По-голямата част от сеизмичните зони на Балканският полуостров не дават възможност за развитие на EEWS. Това се потвърждава и от Vavlas et al. (2021) за района на Гърция.

\section{Заключение}

Балканският полуостров се характеризира с предимно плитки земетресения, с изключение на северозапад във Вранча и субдукционната зона в Егейско море. От друга страна пльтността на СС е сравнително малка и понякога неостатъчна за локализиране на микросеизмичността. Анализът на редица параметри на сеизмичните вълни и земетресенията показва, че в редки случаи може да се разработят ефективни EEWS. В някои случаи подобни системи трябва да се адаптират към характеристиките на дадената С3, а по-голямата част от сеизмичните източници са разположени до големи населени места и в такива случай разработването на такава система е невъзможна.

Благодарности: Изследването е финансирано от ФНИ на СУ „Св. Климент Охридски“ (договор 80-10-77/2021).

\section{Литература \\ References}

Crotwell, H., T. Owens, J. Ritsema. 1999. The TauP Toolkit: Flexible seismic travel-time and ray-path utilities. - Seism. Res. Lett., 70, 154-160; https://doi.org/10.1785/gssrl.70.2.154.

Golitsyn, B. 1960. Selected Works. Vol. 2. Moscow, Acad. Nauk SSSR (in Russian).

Marmureanu, A., C. Ionescu, C. Cioflan. 2011. Advanced realtime acquisition of the Vrancea earthquake early warning system. - Soilid Dynam. Earthquake Engineer., 31, 163169; https://doi.org/10.1016/j.soildyn.2010.10.002.

Nakamura, Y., Y. Saita, T. Sato. 2011. On an earthquake early warning system (EEW) and its applications. - Soilid Dynam. Earthquake Engineer, 31, 2, 127-136; https://doi. org/10.1016/j.soildyn.2010.04.012.

Vavlas, N., A. Kiratzi, Z. Roumelioti. 2021. Source processrelated delays in earthquake early warning for example cases in Greece. - Bull. Seismol. Soc. Amer.; https://doi. org/10.1785/0120200385.

Zollo, A., O. Amoroso, M. Lancieri, Y. Wu, H. Kanamori. 2010. A threshold-based earthquake early warning using dense accelerometer networks. - Geophys. J. Internat., 183, 2, 963-974; https://doi.org/10.1111/j.1365-246 X.2010.04765.x. 